\title{
Probing structural adaptability in templated vanadium selenites
}

Philip D. F. Adler, Rosalind Xu, Jacob H. Olshansky, Matthew D. Smith, Katherine C. Elbert, Yunwen Yang, Gregory M. Ferrence, ${ }^{\S}$ Matthias Zeller, ${ }^{\dagger}$ Joshua Schrier and Alexander J. Norquist*

Department of Chemistry, Haverford College, Haverford PA 19041

${ }^{\dagger}$ Department of Chemistry, Youngstown State University, Youngstown OH 44555

${ }^{\S}$ Department of Chemistry, Illinois State University, Normal IL 61790

\begin{abstract}
The structural adaptability of $\left[\mathrm{V}_{3} \mathrm{O}_{5}\left(\mathrm{SeO}_{3}\right)_{3}\right]_{\mathrm{n}}{ }^{2 \mathrm{n}-}$ layers in organically templated vanadium selenites was determined using a three step approach involving (i) 84 reaction study with 14 distinct organic amines and 6 different reaction conditions, (ii) decision tree construction using both dependent and independent variables, and (iii) the derivation of chemical hypotheses. Formation of $\left[\mathrm{V}_{3} \mathrm{O}_{5}\left(\mathrm{SeO}_{3}\right)_{3}\right]_{\mathrm{n}}{ }^{2 \mathrm{n}-}$ layers requires that three criteria be met. First, compound stabilization through hydrogen-bonding with specific nucleophilic oxide ions is needed, requiring the presence of a primary ammonium site on the respective organic amine. Second, layer formation is facilitated through the use of compact ammonium cations that are able to achieve charge density matching with the anionic layers. Third, competition between organic ammonium cations and $\mathrm{NH}_{4}{ }^{+}$, which affects product formation, can be controlled through reagent choice and initial reactant concentrations. This approach to elucidate structural adaptability is generalizable and can be applied to a range of chemical systems.
\end{abstract}

keywords: vanadium selenites, formation hypotheses, hydrothermal, machine learning, decision tree

\footnotetext{
* Author to whom correspondence should be addressed. Haverford College

370 Lancaster Avenue

Haverford PA, 19041 USA

tel (610) 8962949

fax (610) 8964963

email anorquis@ @averford.edu

http://www.haverford.edu/chem/Norquist/
} 


\title{
Introduction
}

\begin{abstract}
Many solid state structure types can be formed with a wide range of chemical compositions. These 'adaptable' structures; including perovskites,[1, 2] spinels,[3] garnets,[4] and lyonsites[5] to name a few, are able to incorporate a host of different metal cations yet still preserve their inherent connectivities. Such structure types can exhibit a host of desirable physical properties, many of which can be tuned via cation substitution, and have been the focus of intense interest for many decades. Understanding the extent of a structure type's adaptability allows for one to predict which compositions might be stable, leading to the development of tolerance factors, $[6,7]$ based upon ionic radii. Unfortunately, such strategies are not easily extended to inorganic organic hybrid materials owing to the lack of a single metric that describes the complex properties of the organic components.
\end{abstract}

Much like the structure types discussed above, inorganic organic hybrid materials[8-12] can possess a wide range of interesting physical properties, including catalytic activity, molecular sieving, gas adsorption,[13] nonlinear optical properties,[14] and the more recent emergence of hybrid perovskite[15, 16] photovoltaics.[17-21] A primary challenge in probing structural adaptability in these structures stems from the complexity of both the organic structure and the types of interactions that can exist between the organic and inorganic components in materials such as metal-organic frameworks,[22-24] supramolecular compounds[25-28] and organically templated metal oxides.[8,9] The presence of covalent, ionic and coordination bonds, as well as hydrogen-bonding, van der Waals forces and $\pi-\pi$ stacking can make the structural analyses of these interactions difficult.[29] Additionally, the synthesis of such compounds often involves solution phase techniques, which can preclude product stoichiometry control.[30] 
The approach to elucidating structural adaptability in this report focuses on templated $\left[\mathrm{V}_{3} \mathrm{O}_{5}\left(\mathrm{SeO}_{3}\right)_{3}\right]_{\mathrm{n}}{ }^{2 \mathrm{n}-}$ layer-containing compounds and involves three stages. First, 84 chemical reactions were conducted using 14 distinct organic amines and 6 different sets of reaction conditions, in order to cover the maximal descriptor space for reactions from which this layer topology can be formed. Second, a decision tree was constructed using both dependent and independent variables from the experimental data. Third, a series of chemical hypotheses, derived from the decision tree using the informed understanding of a chemist, were used to illuminate the bounds on structural adaptability for templated $\left[\mathrm{V}_{3} \mathrm{O}_{5}\left(\mathrm{SeO}_{3}\right)_{3}\right]_{\mathrm{n}}{ }^{2 \mathrm{n}-}$ layer-containing compounds. Seven new compounds containing templated $\left[\mathrm{V}_{3} \mathrm{O}_{5}\left(\mathrm{SeO}_{3}\right)_{3}\right]_{\mathrm{n}}{ }^{2 \mathrm{n}-}$ layers were synthesized, six of which were structurally characterized using single crystal X-ray diffraction.

\section{Experimental}

Materials. $\mathrm{NH}_{4} \mathrm{VO}_{3}(99 \%), \mathrm{NaVO}_{3}$ (anhydrous, $99.9 \%$ ), $\mathrm{SeO}_{2}(99.4 \%), \mathrm{H}_{2} \mathrm{SeO}_{3}(98$ $\%$ ), ethylenediamine (en, $\geq 99 \%$ ), 1,3-diaminopropane (1,3-dap, $\geq 99 \%$ ), 1,4-diaminobutane dihydrochloride (1,4-dab, $\geq 99.0 \%)$, 1,5-diaminopentane (1,5-dap, $\geq 97 \%$ ), 1,6-diaminohexane (1,6-dah, $98 \%$ ), spermine ( $\geq 97 \%$ ), 3-aminoquinuclidine dihydrochloride (3-aqn, $98 \%), 3$ aminopyrrolidine dihydrochloride (3-apyr, $98 \%$ ), 2-(aminomethyl)piperidine (2-amp, $97 \%$ ), $N, N, N^{\prime}, N^{\prime}$-tetramethyletheylediamine (tmed, $99 \%$ ), piperazine (pip, $99 \%$ ), 2-methylpiperazine (2-mpip, $95 \%)$, 2,5-dimethylpiperazine (2,5-dmpip, $98 \%$ ), and 1,4-diazabicyclo[2.2.2]octane (dabco, $\geq 99.0 \%$ ) were purchased from Sigma-Aldrich. All reagents were used as received. Deionized water was used in these syntheses.

Syntheses. All reactions were conducted in either $23 \mathrm{~mL}$ poly(fluoro-ethylene-propylene) lined pressure vessels or $15 \mathrm{~mL}$ polypropylene bottles. Initial reaction $\mathrm{pHs}$ were controlled by 
the addition of $4 \mathrm{M} \mathrm{HCl}$ and $4 \mathrm{M} \mathrm{NaOH}$. The reactions were heated to a set temperature and allowed to soak. The reactions were then cooled to room temperature at a rate of $6{ }^{\circ} \mathrm{C} \mathrm{h}^{-1}$ to promote the growth of large single crystals. Autoclaves and bottles were opened in air, and products were recovered via vacuum filtration. No additional crystalline or amorphous reaction products were observed.

$\left[\mathrm{C}_{3} \mathrm{H}_{12} \mathbf{N}_{2}\right]\left[\mathrm{V}_{3} \mathrm{O}_{5}\left(\mathrm{SeO}_{3}\right)_{3}\right] \cdot \mathbf{H}_{2} \mathrm{O}$ (1) was synthesized as sheet-like black-green crystals through the reaction of $0.1102 \mathrm{~g}\left(9.42 \times 10^{-4} \mathrm{~mol}\right) \mathrm{NH}_{4} \mathrm{VO}_{3}, 1.0912 \mathrm{~g}\left(9.83 \times 10^{-3} \mathrm{~mol}\right) \mathrm{SeO}_{2}$, $0.4341 \mathrm{~g}\left(5.86 \times 10^{-3} \mathrm{~mol}\right) 1,3$-dap, and $6.056 \mathrm{~g}\left(3.36 \times 10^{-1} \mathrm{~mol}\right) \mathrm{H}_{2} \mathrm{O}$. The reaction was heated at $110{ }^{\circ} \mathrm{C}$ for $24 \mathrm{~h}$ in $23 \mathrm{~mL}$ poly(fluoro-ethylene-propylene) lined pressure vessels; initial $\mathrm{pH}$ was set to 3. IR data $\left(\mathrm{cm}^{-1}\right): \mathrm{O}-\mathrm{H}, 3567 ; \mathrm{C}-\mathrm{H}, 2871 ; \mathrm{N}-\mathrm{H}, 1626,1596,1540,1498,1475 ; \mathrm{V}$ $=\mathrm{O}, 974 ; \mathrm{Se}-\mathrm{O}, 830$. EA obsd (calc): C $5.19 \%(5.09 \%) ; \mathrm{H} 1.96 \%(2.00 \%)$; N $3.92 \%(4.00$ $\%)$; V $22.02 \%(21.60 \%)$; Se $33.91 \%(33.50 \%)$.

$\left[\mathrm{C}_{4} \mathrm{H}_{14} \mathbf{N}_{2}\right]\left[\mathbf{V}_{3} \mathrm{O}_{5}\left(\mathrm{SeO}_{3}\right)_{3}\right]$ (2) was synthesized as sheet-like black-green crystals through the reaction of $0.1382 \mathrm{~g}\left(1.18 \times 10^{-3} \mathrm{~mol}\right) \mathrm{NH}_{4} \mathrm{VO}_{3}, 1.131 \mathrm{~g}\left(1.02 \times 10^{-2} \mathrm{~mol}\right) \mathrm{SeO}_{2}, 0.0930 \mathrm{~g}$ $\left(5.77 \times 10^{-4} \mathrm{~mol}\right) 1,4-\mathrm{dab}$, and $2.055 \mathrm{~g}\left(1.14 \times 10^{-1} \mathrm{~mol}\right) \mathrm{H}_{2} \mathrm{O}$. The reaction was heated at $110^{\circ} \mathrm{C}$ for $24 \mathrm{~h}$ in $23 \mathrm{~mL}$ poly(fluoro-ethylene-propylene) lined pressure vessels; initial $\mathrm{pH}$ was set to 3 . IR data $\left(\mathrm{cm}^{-1}\right): \mathrm{C}-\mathrm{H}, 2919 ; \mathrm{N}-\mathrm{H}, 1656,1525,1465,1385 ; \mathrm{V}=\mathrm{O}, 985,968 ; \mathrm{Se}-\mathrm{O}, 829$. EA obsd (calc): C $6.72 \%(6.82 \%)$; H $1.29 \%(2.00 \%)$; N $3.89 \%(4.00 \%)$; V $21.17 \%(21.70 \%)$; Se $32.74 \%(33.70 \%)$.

$\left[\mathrm{C}_{10} \mathrm{H}_{30} \mathrm{~N}_{4}\right]\left[\mathrm{V}_{3} \mathrm{O}_{5}\left(\mathrm{SeO}_{3}\right)_{3}\right]_{2}(3)$ was synthesized as sheet-like black-green crystals through the reaction of $0.1327 \mathrm{~g}\left(1.13 \times 10^{-3} \mathrm{~mol}\right) \mathrm{NH}_{4} \mathrm{VO}_{3}, 1.039 \mathrm{~g}\left(9.36 \times 10^{-3} \mathrm{~mol}\right) \mathrm{SeO}_{2}, 0.2055 \mathrm{~g}$ $\left(1.02 \times 10^{-3} \mathrm{~mol}\right)$ spermine, and $9.053 \mathrm{~g}\left(5.02 \times 10^{-1} \mathrm{~mol}\right) \mathrm{H}_{2} \mathrm{O}$. The reaction was heated at 110 ${ }^{\circ} \mathrm{C}$ for $24 \mathrm{~h}$ in $23 \mathrm{~mL}$ poly(fluoro-ethylene-propylene) lined pressure vessels; initial $\mathrm{pH}$ was set 
to 3. IR data $\left(\mathrm{cm}^{-1}\right): \mathrm{C}-\mathrm{H}, 2849 ; \mathrm{N}-\mathrm{H}, 1634,1581,1527,1465,1414,1385 ; \mathrm{V}=\mathrm{O}, 982,966$; $\mathrm{Se}-\mathrm{O}, 825$. EA obsd (calc): C $8.36 \%(8.37 \%) ; \mathrm{H} 1.50 \%(2.10 \%)$; N $3.84 \%(3.90 \%)$; V $21.22 \%(21.30 \%) ;$ Se $31.49 \%(33.10 \%)$.

$\left[\mathrm{C}_{4} \mathrm{H}_{12} \mathbf{N}_{2}\right]\left[\mathrm{V}_{3} \mathrm{O}_{5}\left(\mathrm{SeO}_{3}\right)_{3}\right]$ (4) was synthesized as sheet-like black-green crystals through the reaction of $0.1468 \mathrm{~g}\left(1.20 \times 10^{-3} \mathrm{~mol}\right) \mathrm{NH}_{4} \mathrm{VO}_{3}, 0.4460 \mathrm{~g}\left(4.02 \times 10^{-3} \mathrm{~mol}\right) \mathrm{SeO}_{2}, 0.1953 \mathrm{~g}$ $\left(1.23 \times 10^{-3} \mathrm{~mol}\right) 3$-apyr, and $9.072 \mathrm{~g}\left(5.03 \times 10^{-1} \mathrm{~mol}\right) \mathrm{H}_{2} \mathrm{O}$. The reaction was heated at $90{ }^{\circ} \mathrm{C}$ for $24 \mathrm{~h}$ in $23 \mathrm{~mL}$ poly(fluoro-ethylene-propylene) lined pressure vessels; initial $\mathrm{pH}$ was set to 3 . IR data $\left(\mathrm{cm}^{-1}\right): \mathrm{C}-\mathrm{H}, 2996 ; \mathrm{N}-\mathrm{H}, 1635,1596,1532 ; \mathrm{V}=\mathrm{O}, 977 ; \mathrm{Se}-\mathrm{O}, 826$. EA obsd (calc): C $6.52 \%(6.84 \%) ; \mathrm{H} 1.73 \%(1.70 \%)$; N $3.65 \%(4.00 \%)$; V $21.29 \%(21.80 \%)$; Se $33.15 \%$ $(33.80 \%)$

$\left[\mathrm{C}_{6} \mathrm{H}_{16} \mathrm{~N}_{2}\right]\left[\mathrm{V}_{3} \mathrm{O}_{5}\left(\mathrm{SeO}_{3}\right)_{3}\right] \cdot \mathrm{H}_{2} \mathrm{O}$ (5) was synthesized as rod-like black-green crystals through the reaction of $0.1512 \mathrm{~g}\left(1.29 \times 10^{-3} \mathrm{~mol}\right) \mathrm{NH}_{4} \mathrm{VO}_{3}, 1.3820 \mathrm{~g}\left(1.07 \times 10^{-2} \mathrm{~mol}\right) \mathrm{SeO}_{2}$, $0.0891 \mathrm{~g}\left(7.80 \times 10^{-4} \mathrm{~mol}\right) 2$-amp, and $2.126 \mathrm{~g}\left(1.18 \times 10^{-1} \mathrm{~mol}\right) \mathrm{H}_{2} \mathrm{O}$. The reaction was heated at $90{ }^{\circ} \mathrm{C}$ for $48 \mathrm{~h}$ in $15 \mathrm{~mL}$ polypropylene bottles; initial $\mathrm{pH}$ was set to 5 . IR data $\left(\mathrm{cm}^{-1}\right)$ : $\mathrm{O}-\mathrm{H}$, 3448; C - H, 2851; N - H, 1636, 1611, 1541, 1488, 1458; V = O, 982; Se - O, 822. EA obsd (calc): C $10.42 \%$ (9.63\%); H $2.65 \%$ (2.40\%); N $3.62 \%$ (3.70\%); V $21.15 \%$ (20.40\%); Se $31.38 \%(31.70 \%)$

$\left[\mathrm{C}_{7} \mathrm{H}_{14} \mathbf{N}_{2}\right]\left[\mathbf{V}_{3} \mathrm{O}_{5}\left(\mathrm{SeO}_{3}\right)_{3}\right] \cdot \mathrm{H}_{2} \mathrm{O}(6)$ was synthesized as sheet-like black crystals through the reaction of $0.1402 \mathrm{~g}\left(1.15 \times 10^{-3} \mathrm{~mol}\right) \mathrm{NaVO}_{3}, 0.6758 \mathrm{~g}\left(6.09 \times 10^{-3} \mathrm{~mol}\right) \mathrm{SeO}_{2}, 0.1987 \mathrm{~g}$ $\left(9.98 \times 10^{-4} \mathrm{~mol}\right) 3$-aqn, and $6.068 \mathrm{~g}\left(3.37 \times 10^{-1} \mathrm{~mol}\right) \mathrm{H}_{2} \mathrm{O}$. The reaction was heated at $150{ }^{\circ} \mathrm{C}$ for $24 \mathrm{~h}$ in $23 \mathrm{~mL}$ poly(fluoro-ethylene-propylene) lined pressure vessels; initial $\mathrm{pH}$ was set to 3. IR data $\left(\mathrm{cm}^{-1}\right): \mathrm{O}-\mathrm{H}, 3384 ; \mathrm{C}-\mathrm{H}, 3113,2918 ; \mathrm{N}-\mathrm{H}, 1628,1522,1457 ; \mathrm{V}=\mathrm{O}, 981 ; \mathrm{Se}-\mathrm{O}$, 
826. EA obsd (calc): C $10.97 \%$ (11.09\%); H $1.91 \%$ (2.10\%); N $3.64 \%$ (3.70\%); V $19.24 \%$ (20.20\%); Se $39.04 \%(31.30 \%)$.

Compound 7. 7 was synthesized as clusters of black-green crystals through the reaction of $0.1345 \mathrm{~g}\left(1.10 \times 10^{-3} \mathrm{~mol}\right) \mathrm{NH}_{4} \mathrm{VO}_{3}, 1.1383 \mathrm{~g}\left(1.03 \times 10^{-2} \mathrm{~mol}\right) \mathrm{SeO}_{2}, 0.0647 \mathrm{~g}\left(6.00 \times 10^{-4}\right.$ mol) 1,5-dap, and $2.0528 \mathrm{~g}\left(1.1139 \times 10^{-1} \mathrm{~mol}\right) \mathrm{H}_{2} \mathrm{O}$. The reaction was heated at $110{ }^{\circ} \mathrm{C}$ for $24 \mathrm{~h}$ in $23 \mathrm{~mL}$ poly(fluoro-ethylene-propylene) lined pressure vessels; initial $\mathrm{pH}$ was set to 3 . IR data $\left(\mathrm{cm}^{-1}\right): \mathrm{O}-\mathrm{H}, 3408 ; \mathrm{C}-\mathrm{H}, 2988 ; \mathrm{N}-\mathrm{H}, 1627,1599,1558,1541 ; \mathrm{V}=\mathrm{O}, 980 ; \mathrm{Se}-\mathrm{O}, 832$. EA obsd: C $6.16 \%$; H $4.09 \%$; $2.89 \%$; Se $28.17 \%$; V $15.79 \%$.

Single Crystal X-ray Diffraction. Data were collected using a Bruker AXS Smart Apex CCD, ApexII CCD or Quest CMOS diffractometers with Mo-K $\alpha$ radiation $(\lambda=0.71073 \AA)$. The Smart Apex and ApexII instruments featured fine focus sealed tube X-ray sources with graphite monochromators. The Quest CMOS instrument an $\mathrm{I} \mu \mathrm{S}$ microsource with a laterally graded multilayer (Goebel) mirror for monochromatization. A single crystal was mounted on a Mitegen micromesh mount using a trace of mineral oil and cooled in-situ to 100(2) K for data collection. Frames were collected, reflections were indexed and processed, and the files scaled and corrected for absorption using APEX2.[31] The heavy atom positions were determined using SIR92.[32] All other non-hydrogen sites were located from Fourier difference maps. All non-hydrogen sites were refined using anisotropic thermal parameters using full matrix least squares procedures on $F_{o}{ }^{2}$ with $I>3 \sigma(I)$. Hydrogen atoms were placed in geometrically idealized positions. All calculations were performed using Crystals v. 14.23c.[33] Relevant crystallographic data are listed in Table 1.

Powder X-ray Diffraction. Powder diffraction patterns were recorded on a GBCDifftech MMA powder diffractometer. Samples were mounted on glass plates. Calculated 
powder patterns were generated from single crystal data using ATOMS v. 6.0.[34] Powder Xray diffraction patterns were consistent with patterns predicted from the refined structures of $\mathbf{1}$ 6. No evidence of additional phases was observed.

Infrared Spectroscopy. Infrared measurements were obtained using a Perkin Elmer FTIR Spectrum 1000 spectrophotometer. Samples were diluted with spectroscopic grade KBr and pressed into pellets. Scans were collected over the range of $400-4000 \mathrm{~cm}^{-1}$.

Bond Valence Sums. Bond valence sums[35] calculations were performed using parameters compiled by Brese and O'Keeffe.[36] Complete tables of bond valence sums for compounds $\mathbf{1}-\mathbf{6}$ are available in the Supporting Information.

Electronic Structure Calculations. Solid-state electronic structure calculations were performed using ABINIT v. 6.4.1.[37, 38] ABINIT calculations used the Perdew-BurkeErnzerhof generalized gradient approximation (PBE-GGA) exchange-correlation functional, norm-conserving Troullier-Martins pseudopotentials, a planewave basis set with energy cutoff of 25 Hartrees, a $6 \times 6 \times 6$ Monkhorst-Pack k-point sampling grid, and experimental crystal structures. Electron localization functions (ELFs) were calculated from the self-consistent valence electron densities and visualized using Vesta $v$. 3.2.1.[39]

Non-covalent Interaction (NCI) Index Calculations. NCI analyses were performed using CRITIC 2 version $1.0[40,41]$ to generate promolecular densities from the default numerical free-atom densities, using an approach similar as described in a previous report.[29] The extraction of isosurfaces corresponding to particular interactions was performed using Mathematica 10.0.0.0 (see Supporting Information), and visualized using Vesta v. 3.2.1.

Decision tree generation. A decision tree was generated using Weka, ${ }^{14}$ and is a $\mathrm{J} 48$ decision tree, which is a java implementation of the C4.5 decision tree algorithm. ${ }^{15}$ The 
algorithm is provided with the full set of descriptors, which are provided in the Supplementary data, and selects the descriptors that produces the 'best' split of the data. See Table 2 for a list of descriptors. Heuristically, the best split is the one that most accurately separates the greatest number of results. In order to aid interpretation of the decision tree, a correlation matrix was calculated between all of the molecular descriptors that had been calculated. This correlation matrix is available in the Supplementary Data. Training and testing was performed on all 84 reactions. Maximal projection areas were calculated using ChemAxon Calculator Plugin.[42]

\section{Results and Discussion}

The $\left[\mathrm{V}_{3} \mathrm{O}_{5}\left(\mathrm{SeO}_{3}\right)_{3}\right]_{\mathrm{n}}{ }^{2 \mathrm{n}-}$ layers shown in Figure 1 are observed in a range of different organically templated vanadium selenites, in which a diverse set of organic amines are included. $\left[\mathrm{C}_{2} \mathrm{H}_{10} \mathrm{~N}_{2}\right]\left[\mathrm{V}_{3} \mathrm{O}_{5}\left(\mathrm{SeO}_{3}\right)_{3}\right] \cdot 1.25 \mathrm{H}_{2} \mathrm{O}[43]$ contains ethylenediammoniun cations, $\left[\mathrm{C}_{2} \mathrm{H}_{10} \mathrm{~N}_{2}\right]^{2+}$, while compounds $\mathbf{1}-\mathbf{7}$ include $\left[1,3-\mathrm{dapH}_{2}\right]^{2+},\left[1,4-\mathrm{dapH}_{2}\right]^{2+},\left[\text { spermineH }_{4}\right]^{4+},\left[3-\mathrm{apyrH}_{2}\right]^{2+}, \quad[2-$ $\left.\mathrm{ampH}_{2}\right]^{2+}\left[3-\mathrm{aqnH}_{2}\right]^{2+}$, and $\left[1,5-\mathrm{dapH}_{2}\right]^{2+}$ respectively. While these amines differ in structure and charge, their corresponding $\left[\mathrm{V}_{3} \mathrm{O}_{5}\left(\mathrm{SeO}_{3}\right)_{3}\right]_{\mathrm{n}}{ }^{2 \mathrm{n}-}$ layers are essentially the same. These layers consist of clusters comprised of six edge shared $\left[\mathrm{VO}_{6}\right]$ polyhedra, which are linked to one another by $\left[\mathrm{SeO}_{3}\right]^{2-}$ groups. The vanadium oxide clusters contain both $\mathrm{V}^{4+}$ and $\mathrm{V}^{5+}$ centers, these oxidation states were determined using bond valence sums. The $\mathrm{V}^{4+}$ sites are located on the ends of each cluster, while the $\mathrm{V}^{5+}$ sites occupy the four central sites. The coordination polyhedra containing $\mathrm{V}^{4+}$ sites are shown in green while those containing $\mathrm{V}^{5+}$ are shown as orange octahedra in Figures 1 - 4. The calculated bond valence sums for the $\mathrm{V}^{4+}$ sites in compounds 1 6 range from 4.17 to $4.22 \mathrm{vu}$, while the $\mathrm{V}^{5+}$ sites have values of $4.99-5.11$ vu. Corresponding 
differences in $\mathrm{V}-\mathrm{O}_{\text {bridging }}$ and $\mathrm{V}-\mathrm{O}_{\text {terminal }}$ bond lengths are observed. See Table 3. The decreased bond distances in $\mathrm{V}^{5+}-\mathrm{O}$ with respect to $\mathrm{V}^{4+}-\mathrm{O}$ are a result of the increased charge on the vanadium center.

The three dimensional structures of compounds $\mathbf{1}-\mathbf{6}$ and $\left[\mathrm{C}_{2} \mathrm{H}_{10} \mathrm{~N}_{2}\right]\left[\mathrm{V}_{3} \mathrm{O}_{5}\left(\mathrm{SeO}_{3}\right)_{3}\right] \cdot 1.25 \mathrm{H}_{2} \mathrm{O}[43]$ are similar to one another. The organic cations reside between $\left[\mathrm{V}_{3} \mathrm{O}_{5}\left(\mathrm{SeO}_{3}\right)_{3}\right]_{\mathrm{n}}^{2 \mathrm{n}-}$ layers, creating three-dimensional hydrogen-bonding networks. Some compounds, $\left[\mathrm{C}_{2} \mathrm{H}_{10} \mathrm{~N}_{2}\right]\left[\mathrm{V}_{3} \mathrm{O}_{5}\left(\mathrm{SeO}_{3}\right)_{3}\right] \cdot 1.25 \mathrm{H}_{2} \mathrm{O}, \mathbf{1}, 5$ and $\mathbf{6}$, contain occluded water molecules, which also participate in the hydrogen-bonding networks. Three dimensional packing figures are shown in Figure $2-4$.

The existence of a series of compounds containing isotypic $\left[\mathrm{V}_{3} \mathrm{O}_{5}\left(\mathrm{SeO}_{3}\right)_{3}\right]_{\mathrm{n}}{ }^{2 \mathrm{n}-}$ layers, despite the presence of a range of structurally diverse organic amines and a large set of different reported inorganic structures in templated vanadium selenites,[43-52] prompted us to consider the bounds on the structural adaptability for these layers. Two questions were raised. First, which amines can possibly be incorporated into compounds containing $\left[\mathrm{V}_{3} \mathrm{O}_{5}\left(\mathrm{SeO}_{3}\right)_{3}\right]_{\mathrm{n}}{ }^{2 \mathrm{n}-}$ layers? Second, for the amines than can be incorporated, how do the synthetic windows differ between amines? To answer these questions, 84 individual reactions were conducted, containing six different sets of reaction conditions and 14 distinct organic amines.

The amines included in this study were selected to cover a range in both structural and chemical diversity. Amines containing only primary (en, 1,3-dap, 1,4-dab, 1,5-dap, 1,6-dah), only secondary (pip, 2-mpip, 2,5-dmpip), or only tertiary sites (tmed, dabco) were used as well as amines containing both primary and secondary (spermine, 3-apyr, 2-amp) and primary and tertirary (3-aqn). A range of both linear amines and cyclic amines were chosen. The linear amines ranged in length from en to 1,6-dah and spermine. Structural diversity within the cyclic 
number of ammonium sites. Descriptors that are strongly correlated to other descriptors (introducing redundancies), chemically meaningless or contain missing values should not be included in this type of analysis.

Two approaches to the generation of decision trees exist. Decision trees optimized for predictive purposes are 'pruned' as an aspect of the algorithm, whereby branches on the tree for which the evidence is tenuous are removed to prevent over-modeling. Decision trees optimized for explanatory purposes are not pruned, and generally yield more precise categorizations of the data on which they are trained. The goal of 'pruned' decisions three is to categorize the training data as precisely as possible, allowing complex patterns to be found in the data. Cross-validation is not required because no statistical meaning is derived from the decision tree, but it is therefore essential to have a domain expert (in this case, a chemist) ensure that splits in the tree make chemical sense. The decision tree shown in Figure 7 is optimized for explanatory purposes and was created without pruning because the intended purpose of this tree was to generate chemical hypotheses regarding the reactions involved. These hypotheses cannot be generated in isolation from the expert chemist; the chemical understanding of such an expert is requisite to extract meaning from the descriptors.

Inspection of the decision tree shown in Figure 7 exposes the limits to the compositional adaptability of $\left[\mathrm{V}_{3} \mathrm{O}_{5}\left(\mathrm{SeO}_{3}\right)_{3}\right]_{\mathrm{n}}{ }^{2 \mathrm{n}-}$ layers in templated compounds. Specifically, the reaction and reactant characteristics required for layer formation under any of the reaction conditions explored can be determined. Moreover, for amines that are able to be incorporated into $\left[\mathrm{V}_{3} \mathrm{O}_{5}\left(\mathrm{SeO}_{3}\right)_{3}\right]_{\mathrm{n}}^{2 \mathrm{n}-}$ compounds, we can understand the variable 'success' rates as a function of reaction conditions. Three specific hypotheses were generated. First, amines must include a primary ammonium site in order to satisfy the hydrogen-bonding requirements of the $\left[\mathrm{V}_{3} \mathrm{O}_{5}\left(\mathrm{SeO}_{3}\right)_{3}\right]_{\mathrm{n}}{ }^{2 \mathrm{n}-}$ layers. Second, 

containing compounds. Third, the use of $\mathrm{NH}_{4} \mathrm{VO}_{3}$ as a reagent introduces alternate products that compete with the desired phases.

It is clear from the reaction grid that amines without primary ammonium sites do not form $\left[\mathrm{V}_{3} \mathrm{O}_{5}\left(\mathrm{SeO}_{3}\right)_{3}\right]_{\mathrm{n}}{ }^{2 \mathrm{n}}$-layer containing compounds under any of the reaction conditions explored. See Figure 6. The importance of this property is indicated by the fact that the first selector in the decision tree is the presence or absence of primary ammonium sites on the organic ammonium cations, shown in the blue component of Figure 7. Five of the amines tested in this study (tmed, pip, 2-mpip, 2,5-dmpip and dabco) do not contain primary ammonium cations and are not incorporated into compounds containing $\left[\mathrm{V}_{3} \mathrm{O}_{5}\left(\mathrm{SeO}_{3}\right)_{3}\right]_{\mathrm{n}}{ }^{2 \mathrm{n}-}$ layers in any of the 84 reactions conducted. Templated vanadium selenites with different inorganic structures have, however, been reported for pip,[52] 2-mpip,[44, 46] 2,5-dmpip,[46] and dabco,[43] which suggests that these amines are not completely incompatible with vanadium selenite structures. As such, their absence in $\left[\mathrm{V}_{3} \mathrm{O}_{5}\left(\mathrm{SeO}_{3}\right)_{3}\right]_{\mathrm{n}}{ }^{2 \mathrm{n}-}$ layer containing phases needs to be explained. Inspection of the three-dimensional packing arrangements of $\left[\mathrm{C}_{2} \mathrm{H}_{10} \mathrm{~N}_{2}\right]\left[\mathrm{V}_{3} \mathrm{O}_{5}\left(\mathrm{SeO}_{3}\right)_{3}\right] \cdot 1.25 \mathrm{H}_{2} \mathrm{O}$ and compounds $\mathbf{1}-\mathbf{6}$, shown in Figures $2-4$, reveals that the primary ammonium sites reside on the same general position in each compound. A pocket exists within each $\left[\mathrm{V}_{3} \mathrm{O}_{5}\left(\mathrm{SeO}_{3}\right)_{3}\right]_{\mathrm{n}}{ }^{2 \mathrm{n}-}$ layer, sitting between four adjacent vanadium oxide dimers. See Figure 8 . It is in this pocket that the primary ammonium cations reside, donating three hydrogen bonds to neighboring oxide anions. In each case, the hydrogen-bond acceptors include the only terminal $\mathrm{Se}=\mathrm{O}$ oxide anion sites, which exhibit the highest nucleophilicities,[55-61] as determined using bond valence sums, $[35,36]$ rendering them attractive to hydrogen bond donors. The hydrogen-bonding interactions in these pockets were identified and visualized using non-covalent interaction (NCI) 
index calculations. Three distinct isosurfaces, corresponding to $\mathrm{N}-\mathrm{H} \cdots \mathrm{O}$ hydrogen bonds, were observed in each hydrogen-bonding pocket, confirming their assignment. Graphics of these isosurfaces and NCI fingerprints are available for compounds $1-6$ in the Supplementary Data. The formation of hydrogen-bonding interactions in these pockets stabilizes the $\left[\mathrm{V}_{3} \mathrm{O}_{5}\left(\mathrm{SeO}_{3}\right)_{3}\right]_{n}^{2 \mathrm{n}-}$ layers and allows for product formation.

The need for charge density matching[53-55, 62, 63] between the cationic organic and anionic inorganic components in the formation of $\left[\mathrm{V}_{3} \mathrm{O}_{5}\left(\mathrm{SeO}_{3}\right)_{3}\right]_{\mathrm{n}}{ }^{2 \mathrm{n}-}$ layer-containing compounds is manifested in the decision tree, highlighted as the green regions in Figure 7 . The $\left[\mathrm{V}_{3} \mathrm{O}_{5}\left(\mathrm{SeO}_{3}\right)_{3}\right]_{\mathrm{n}}{ }^{2 \mathrm{n}-}$ layers exhibit little flection,[61] with ranges in layer metrics differing by only $0.4 \%$. As the areas and charges of the $\left[\mathrm{V}_{3} \mathrm{O}_{5}\left(\mathrm{SeO}_{3}\right)_{3}\right]_{\mathrm{n}}{ }^{2 \mathrm{n}-}$ layers in $\left[\mathrm{C}_{2} \mathrm{H}_{10} \mathrm{~N}_{2}\right]\left[\mathrm{V}_{3} \mathrm{O}_{5}\left(\mathrm{SeO}_{3}\right)_{3}\right] \cdot 1.25 \mathrm{H}_{2} \mathrm{O}$ and compounds $\mathbf{1}-\mathbf{6}$ are essentially fixed, the components of the interlayer spaces must balance the negative charges on these layers. The second selector in the decision tree quantifies the charge density of the amine as being equal to the amine's maximal projection area divided by the number of nitrogen atoms it contains, with the assumption that each ammonium has a formal charge of +1 . Eleven of the twelve reactions involving amines with high values fail to result in $\left[\mathrm{V}_{3} \mathrm{O}_{5}\left(\mathrm{SeO}_{3}\right)_{3}\right]_{\mathrm{n}}{ }^{2 \mathrm{n}-}$ layer-containing compounds because the charge per unit area values are insufficient for charge density matching to be achieved. 1,5-dap and 1,6-dah are the two amines involved in these twelve reactions.

All of the linear diamines used in this study exist as +2 cations under the conditions explored. Ethylenediamine (en), $\left[1,3-\mathrm{dapH}_{2}\right]^{2+}$ and $\left[1,4-\mathrm{dapH}_{2}\right]^{2+}$, are able to achieve charge density matching with the $\left[\mathrm{V}_{3} \mathrm{O}_{5}\left(\mathrm{SeO}_{3}\right)_{3}\right]_{\mathrm{n}}{ }^{2 \mathrm{n}-}$ layers in $\left[\mathrm{C}_{2} \mathrm{H}_{10} \mathrm{~N}_{2}\right]\left[\mathrm{V}_{3} \mathrm{O}_{5}\left(\mathrm{SeO}_{3}\right)_{3}\right] \cdot 1.25 \mathrm{H}_{2} \mathrm{O}, \mathbf{1}$ and 2, respectively because their respective projection areas are small. Elongation of these cations to $\left[1,5-\mathrm{dapH}_{2}\right]^{2+}$ and $\left[1,6-\mathrm{dahH}_{2}\right]^{2+}$, in contrast, makes charge density matching more difficult 
because cation charge remains fixed at +2 , while cation size increases. It was expected that the inclusion of $\left[1,5-\mathrm{dapH}_{2}\right]^{2+}$ or $\left[1,6-\mathrm{dahH}_{2}\right]^{2+}$ would either be difficult or impossible, because the respective charge densities of these cations are insufficient. As observed in Figure 6, no reactions were successful with 1,6-dah, regardless of the reaction composition or conditions applied. A lone example of a $\left[\mathrm{V}_{3} \mathrm{O}_{5}\left(\mathrm{SeO}_{3}\right)_{3}\right]_{\mathrm{n}}{ }^{2 \mathrm{n}-}$ layer-containing compound with [1,5-dapH $\left.{ }_{2}\right]^{2+}$ cations exists, denoted compound 7. As expected, this sample did not contain large high quality single crystals, instead smaller crystallites of lower quality were observed. These crystallites were of insufficient size and quality for single crystal X-ray diffraction data collection. However, formation of a $\left[\mathrm{V}_{3} \mathrm{O}_{5}\left(\mathrm{SeO}_{3}\right)_{3}\right]_{\mathrm{n}}{ }^{2 \mathrm{n}-}$ layer-containing compound is supported by three lines of evidence. First, the powder X-ray diffraction of $\mathbf{7}$ strongly resembles the patterns of $\mathbf{1}$ 6. Powder X-ray diffraction patterns for all compounds are available in the Supplementary Data. In each case, the two most intense peaks correspond to reflections aligned with the $\left[\mathrm{V}_{3} \mathrm{O}_{5}\left(\mathrm{SeO}_{3}\right)_{3}\right]_{\mathrm{n}}^{2 \mathrm{n-}}$ layers; $020 / 060$ for $\mathbf{1}, 011 / 033$ for $\mathbf{2}$ and $\mathbf{3}, 010 / 030$ for $\mathbf{4}-\mathbf{6}$. This suggests that while the $\left[\mathrm{V}_{3} \mathrm{O}_{5}\left(\mathrm{SeO}_{3}\right)_{3}\right]_{\mathrm{n}}{ }^{2 \mathrm{n}-}$ layers are present in $\mathbf{7}$, periodicity between layers is less well defined owing to difficulty in charge density matching. Second, the color of the crystallites is similar to compounds $\mathbf{1}-\mathbf{6}$, suggesting the presence of intervalence charge transfer bands between adjacent $\mathrm{V}^{4+}$ and $\mathrm{V}^{5+}$ centers. A photograph of $\left[\mathrm{C}_{2} \mathrm{H}_{10} \mathrm{~N}_{2}\right]\left[\mathrm{V}_{3} \mathrm{O}_{5}\left(\mathrm{SeO}_{3}\right)_{3}\right] \cdot 1.25 \mathrm{H}_{2} \mathrm{O}$ and compounds $\mathbf{1}-\mathbf{7}$ is available in the Supplementary Data. Third, elemental analyses resulted in an approximate $1: 1$ ratio between $\mathrm{V}$ and $\mathrm{Se}$, which corresponds to the stoichiometry of the $\left[\mathrm{V}_{3} \mathrm{O}_{5}\left(\mathrm{SeO}_{3}\right)_{3}\right]_{\mathrm{n}}^{2 \mathrm{n}-}$ layers.

The $\left[\text { spermine } H_{4}\right]^{4+}$ cations in $\mathbf{3}$ differ distinctly from the other linear amines described above in that they include four ammonium centers on each cation and contain both primary and secondary sites. Their increased nitrogen count and subsequent charge on each $\left[\text { spermine } \mathrm{H}_{4}\right]^{4+}$ 
same dependencies on reaction conditions are not observed for these compounds in the decision tree.

Conclusion. The structural adaptability of $\left[\mathrm{V}_{3} \mathrm{O}_{5}\left(\mathrm{SeO}_{3}\right)_{3}\right]_{\mathrm{n}}{ }^{2 \mathrm{n}-}$ layers in templated vanadium selenites arises from complicated non-covalent interactions between the cationic organic and anionic inorganic components. Using the results of a series of experiments with varying amine structure and reaction conditions, combined with relevant molecular characteristic descriptors, enabled the construction of a decision tree that reveals new chemical hypotheses about the rules governing layer formation. More generally, this approach can be used to understand the factors governing structural adaptability of inorganic-organic hybrid materials. Stabilization and crystallization of $\left[\mathrm{V}_{3} \mathrm{O}_{5}\left(\mathrm{SeO}_{3}\right)_{3}\right]_{\mathrm{n}}{ }^{2 \mathrm{n}-}$ layers requires amines with (a) primary ammonium sites, in order to satisfy the hydrogen-bonding requirements of the $\left[\mathrm{V}_{3} \mathrm{O}_{5}\left(\mathrm{SeO}_{3}\right)_{3}\right]_{\mathrm{n}}{ }^{2 \mathrm{n}-}$ layers, (b) sufficient charge densities to balance the charge of the $\left[\mathrm{V}_{3} \mathrm{O}_{5}\left(\mathrm{SeO}_{3}\right)_{3}\right]_{\mathrm{n}}{ }^{2 \mathrm{n}}$-layer containing compounds, and (c) conditions that bias the organic amines to form extended hydrogen-bonding networks.

Acknowledgements. The authors acknowledge support from the NSF (Award No. DMR1307801), A.N. and J.S. acknowledge the Henry Dreyfus Teacher-Scholar Awards Program and grants to Haverford College from the HHMI Undergraduate Science Education Program. M.Z. acknowledges support for the purchase of a diffractometer from the NSF grant 1337296, the Ohio Board of Regents grant CAP-491 and from Youngstown State University. GF acknowledges the NSF (Award No. CHE-1039689) for funding ISU's X-ray diffractometer. This research used computational resources of the National Energy Research Scientific 
Computing Center (NERSC), which is supported by the Office of Science of the U.S.

Department of Energy

under Contract No. DE-AC02-05CH11231.

Supplementary Data Available. Crystallographic data for the structure reported in this paper have been deposited with the Cambridge Crystallographic Data Centre as supplementary publication numbers 1426702 - 1426707. Tables of bond valence sums and NCI analyses and hydrogen-bonding figures for compounds $\mathbf{1}-\mathbf{6}$, and powder X-ray diffraction patterns and optical photographs of compounds $\mathbf{1}-\mathbf{7}$. 
Table 1. Crystallographic data for compounds 1 - 6 .

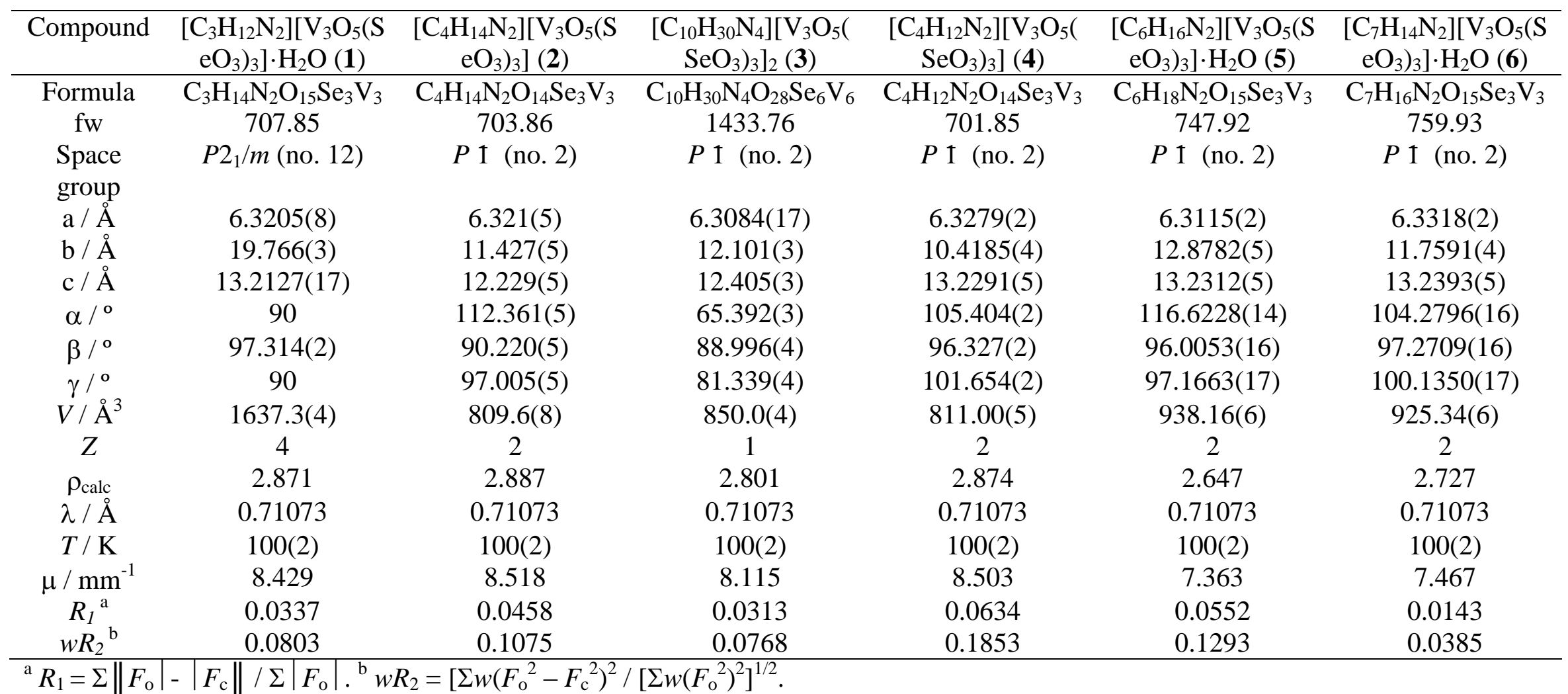


1 Table 2. A list of the descriptors included in the decision tree creation, separated by function.

\begin{tabular}{|c|c|c|}
\hline $\begin{array}{l}3-\text { Type } \\
4\end{array}$ & Subset & Descriptor \\
\hline \multirow{6}{*}{$\begin{array}{l}5 \\
6 \\
6 \\
7 \\
8 \\
9 \\
0 \\
0 \\
1\end{array}$} & \multirow[t]{3}{*}{ Stoichiometry } & Amine amount (moles) \\
\hline & & Vanadium amount (moles) \\
\hline & & Selenium amount (moles) \\
\hline & \multirow[t]{3}{*}{ Conditions } & Initial $\mathrm{pH}$ \\
\hline & & Time at maximum temperature \\
\hline & & Maximum temperature \\
\hline \multirow{11}{*}{$\begin{array}{ll}2 & \text { Amine } \\
3 & \\
4 & \\
5 \\
6 \\
7 \\
8\end{array}$} & \multirow[t]{7}{*}{ Amine structure } & Chain length \\
\hline & & Molecular weight \\
\hline & & Bond count \\
\hline & & Nitrogen count \\
\hline & & Primary ammonium site (yes/no) \\
\hline & & Cyclic structure (yes/no) \\
\hline & & Spherical (yes/no) \\
\hline & \multirow[t]{2}{*}{ Amine acidity } & Minimum $\mathrm{pK}_{\mathrm{a}}$ \\
\hline & & Maximum $\mathrm{pK}_{\mathrm{a}}$ \\
\hline & Charge density & Maximal projection area / nitrogen \\
\hline & General properties & Reagent is an $\mathrm{HCl}$ salt (yes/no) \\
\hline \multirow{2}{*}{ Inorganics } & \multirow[t]{2}{*}{ Vanadium counter ions } & Vanadium source contains $\mathrm{NH}_{4}^{+}$(yes/no) \\
\hline & & Vanadium source contains $\mathrm{Na}^{+}$(yes/no) \\
\hline
\end{tabular}

28 
1 Table 3. Bond length and bond valence ranges for $\mathrm{V}-\mathrm{O}$ interactions in compound $\mathbf{1}-\mathbf{6}$.

2

\begin{tabular}{ccc}
\hline & \multicolumn{2}{c}{ Bond distances $(\AA)$ and bond valence ranges $(\mathrm{vu})$} \\
Species & $\mathrm{V}-\mathrm{O}_{\text {terminal }}$ & $\mathrm{V}-\mathrm{O}_{\text {bridging }}$ \\
\hline $\mathrm{V}^{4+}-\mathrm{O}$ & $1.596(3)-1.609(7)$ & $1.916(7)-2.516(3)$ \\
& $1.66-1.60$ & $0.70-0.14$ \\
$\mathrm{~V}^{5+}-\mathrm{O}$ & $1.584(8)-1.600(3)$ & $1.735(5)-2.422(6)$ \\
& $1.81-1.73$ & $1.20-0.19$ \\
\hline
\end{tabular}



Figure 1. Polyhedral representation of the $\left[\mathrm{V}_{3} \mathrm{O}_{5}\left(\mathrm{SeO}_{3}\right)_{3}\right]_{\mathrm{n}}{ }^{2 \mathrm{n}-}$ layers found in compounds $\mathbf{1}-\mathbf{7}$ and
$\left[\mathrm{C}_{2} \mathrm{H}_{10} \mathrm{~N}_{2}\right]\left[\mathrm{V}_{3} \mathrm{O}_{5}\left(\mathrm{SeO}_{3}\right)_{3}\right] \cdot 1.25 \mathrm{H}_{2} \mathrm{O}$. Green and orange polyhedra represent $\left[\mathrm{V}^{4+} \mathrm{O}_{6}\right]$ and $\left[\mathrm{V}^{5+} \mathrm{O}_{6}\right]$, respectively, while purple and red spheres represent selenium and oxygen. ELF isosurfaces are shown with a boundary condition of 0.96 .

Figure 2. Three-dimensional packing figures of (a) $\left[\mathrm{C}_{2} \mathrm{H}_{10} \mathrm{~N}_{2}\right]\left[\mathrm{V}_{3} \mathrm{O}_{5}\left(\mathrm{SeO}_{3}\right)_{3}\right] \cdot 1.25 \mathrm{H}_{2} \mathrm{O}$, (b) $\left[\mathrm{C}_{4} \mathrm{H}_{14} \mathrm{~N}_{2}\right]\left[\mathrm{V}_{3} \mathrm{O}_{5}\left(\mathrm{SeO}_{3}\right)_{3}\right]$ (1) and (c) $\left[\mathrm{C}_{4} \mathrm{H}_{14} \mathrm{~N}_{2}\right]\left[\mathrm{V}_{3} \mathrm{O}_{5}\left(\mathrm{SeO}_{3}\right)_{3}\right]$ (2). Green and orange polyhedra represent $\left[\mathrm{V}^{4+} \mathrm{O}_{6}\right]$ and $\left[\mathrm{V}^{5+} \mathrm{O}_{6}\right]$, respectively, while purple, red, blue, white and gray spheres represent selenium, oxygen, nitrogen, carbon and hydrogen, respectively. Organic ammonium cation hydrogen atoms have been omitted for clarity.

Figure 3. Three-dimensional packing figure of $\left[\mathrm{C}_{10} \mathrm{H}_{30} \mathrm{~N}_{4}\right]\left[\mathrm{V}_{3} \mathrm{O}_{5}\left(\mathrm{SeO}_{3}\right)_{3}\right]_{2}(3)$. Green and orange polyhedra represent $\left[\mathrm{V}^{4+} \mathrm{O}_{6}\right]$ and $\left[\mathrm{V}^{5+} \mathrm{O}_{6}\right]$, respectively, while purple, red, blue, white and gray spheres represent selenium, oxygen, nitrogen, carbon and hydrogen, respectively. Organic ammonium cation hydrogen atoms have been omitted for clarity.

Figure 4. Three-dimensional packing figures of (a) $\left[\mathrm{C}_{4} \mathrm{H}_{12} \mathrm{~N}_{2}\right]\left[\mathrm{V}_{3} \mathrm{O}_{5}\left(\mathrm{SeO}_{3}\right)_{3}\right]$ (4), $\left[\mathrm{C}_{6} \mathrm{H}_{16} \mathrm{~N}_{2}\right]\left[\mathrm{V}_{3} \mathrm{O}_{5}\left(\mathrm{SeO}_{3}\right)_{3}\right] \cdot \mathrm{H}_{2} \mathrm{O}$ (5) and (c) $\left[\mathrm{C}_{7} \mathrm{H}_{14} \mathrm{~N}_{2}\right]\left[\mathrm{V}_{3} \mathrm{O}_{5}\left(\mathrm{SeO}_{3}\right)_{3}\right] \cdot \mathrm{H}_{2} \mathrm{O}$ (6). Green and orange polyhedra represent $\left[\mathrm{V}^{4+} \mathrm{O}_{6}\right]$ and $\left[\mathrm{V}^{5+} \mathrm{O}_{6}\right]$, respectively, while purple, red, blue, white and gray spheres represent selenium, oxygen, nitrogen, carbon and hydrogen, respectively. Organic ammonium cation hydrogen atoms have been omitted for clarity.

Figure 5. The fourteen amines used in this study.

Figure 6. Reaction outcomes as a function of conditions and amine identity.

Figure 7. $\left[\mathrm{V}_{3} \mathrm{O}_{5}\left(\mathrm{SeO}_{3}\right)_{3}\right]_{\mathrm{n}}{ }^{2 \mathrm{n}-}$ layer formation decision tree. Selection of primary amines is shown in blue, selection by charge density matching is shown in green, and selection by vanadium source is shown in red. Each reaction bin contains a specific reaction outcome value and numbers of reactions correctly and incorrectly assigned to that bin, respectively.

Figure 8. Local hydrogen-bonding environments for the primary ammonium sites in compounds $\mathbf{1}-\mathbf{6}$. 


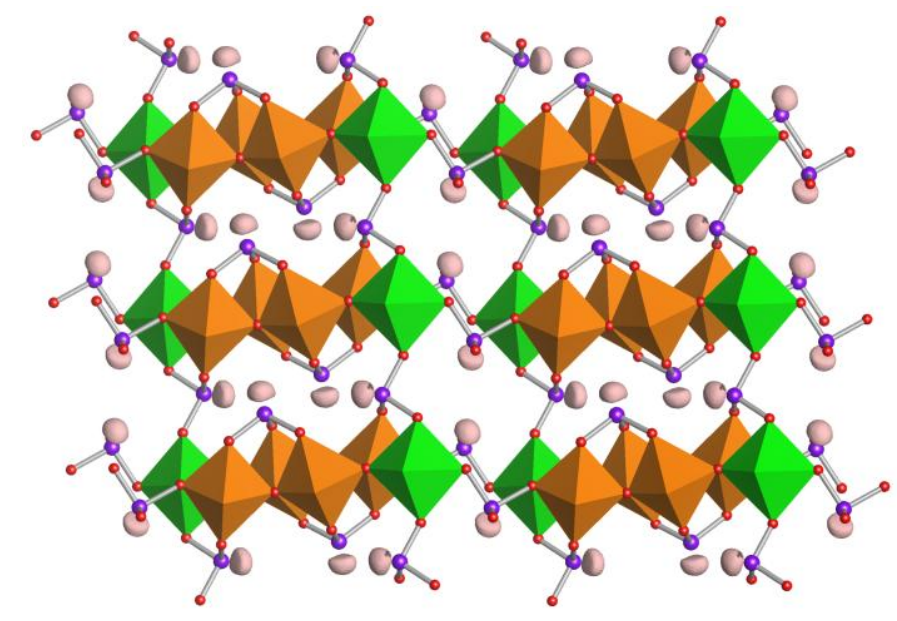

Figure 1. Polyhedral representation of the $\left[\mathrm{V}_{3} \mathrm{O}_{5}\left(\mathrm{SeO}_{3}\right)_{3}\right]_{\mathrm{n}}{ }^{2 \mathrm{n}-}$ layers found in compounds $\mathbf{1}-\mathbf{7}$ and $\left[\mathrm{C}_{2} \mathrm{H}_{10} \mathrm{~N}_{2}\right]\left[\mathrm{V}_{3} \mathrm{O}_{5}\left(\mathrm{SeO}_{3}\right)_{3}\right] \cdot 1.25 \mathrm{H}_{2} \mathrm{O}$. Green and orange polyhedra represent $\left[\mathrm{V}^{4+} \mathrm{O}_{6}\right]$ and $\left[\mathrm{V}^{5+} \mathrm{O}_{6}\right]$, respectively, while purple and red spheres represent selenium and oxygen. ELF isosurfaces are shown with a boundary condition of 0.96 . 

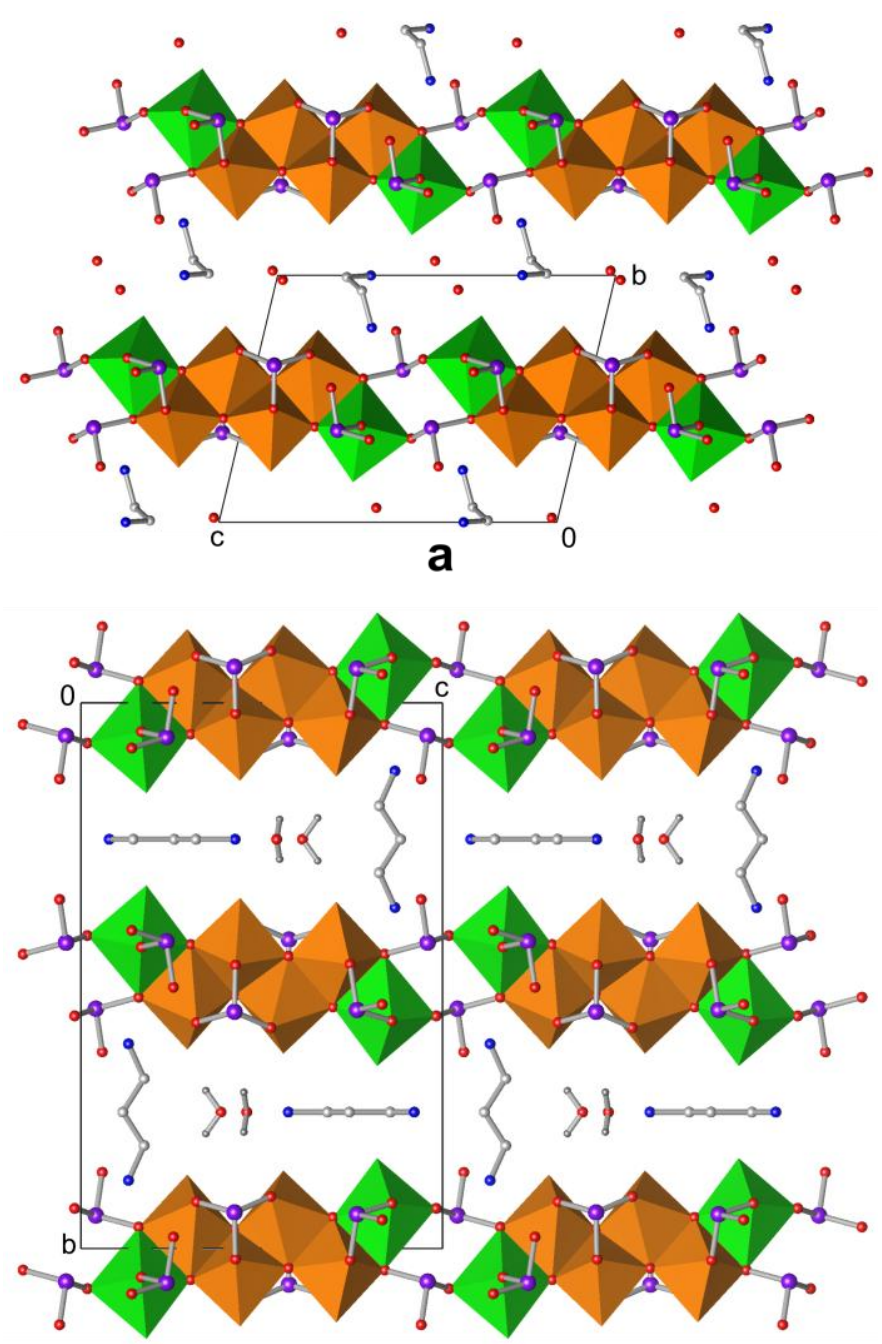

b

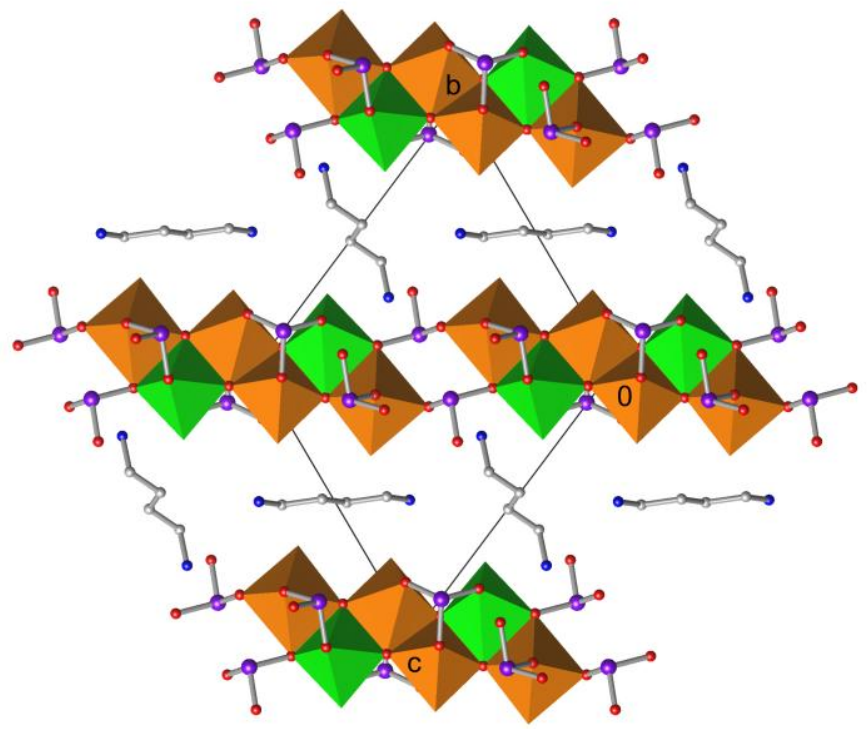

C

Figure 2. Three-dimensional packing figures of (a) $\left[\mathrm{C}_{2} \mathrm{H}_{10} \mathrm{~N}_{2}\right]\left[\mathrm{V}_{3} \mathrm{O}_{5}\left(\mathrm{SeO}_{3}\right)_{3}\right] \cdot 1.25 \mathrm{H}_{2} \mathrm{O}$, (b) $\left[\mathrm{C}_{4} \mathrm{H}_{14} \mathrm{~N}_{2}\right]\left[\mathrm{V}_{3} \mathrm{O}_{5}\left(\mathrm{SeO}_{3}\right)_{3}\right]$ (1) and (c) $\left[\mathrm{C}_{4} \mathrm{H}_{14} \mathrm{~N}_{2}\right]\left[\mathrm{V}_{3} \mathrm{O}_{5}\left(\mathrm{SeO}_{3}\right)_{3}\right]$ (2). Green and orange polyhedra represent $\left[\mathrm{V}^{4+} \mathrm{O}_{6}\right]$ and $\left[\mathrm{V}^{5+} \mathrm{O}_{6}\right]$, respectively, while purple, red, blue, white and gray spheres represent selenium, oxygen, nitrogen, carbon and hydrogen, respectively. Organic ammonium cation hydrogen atoms have been omitted for clarity. 


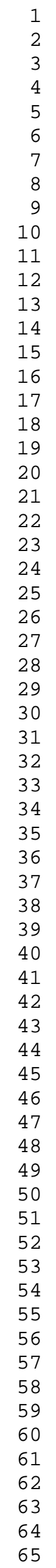




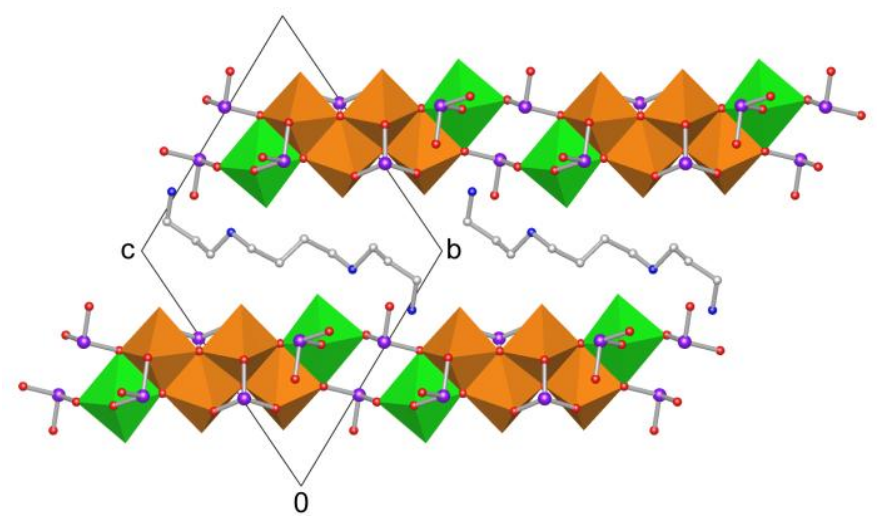

Figure 3. Three-dimensional packing figure of $\left[\mathrm{C}_{10} \mathrm{H}_{30} \mathrm{~N}_{4}\right]\left[\mathrm{V}_{3} \mathrm{O}_{5}\left(\mathrm{SeO}_{3}\right)_{3}\right]_{2}(3)$. Green and orange polyhedra represent $\left[\mathrm{V}^{4+} \mathrm{O}_{6}\right]$ and $\left[\mathrm{V}^{5+} \mathrm{O}_{6}\right]$, respectively, while purple, red, blue, white and gray spheres represent selenium, oxygen, nitrogen, carbon and hydrogen, respectively. Organic ammonium cation hydrogen atoms have been omitted for clarity. 


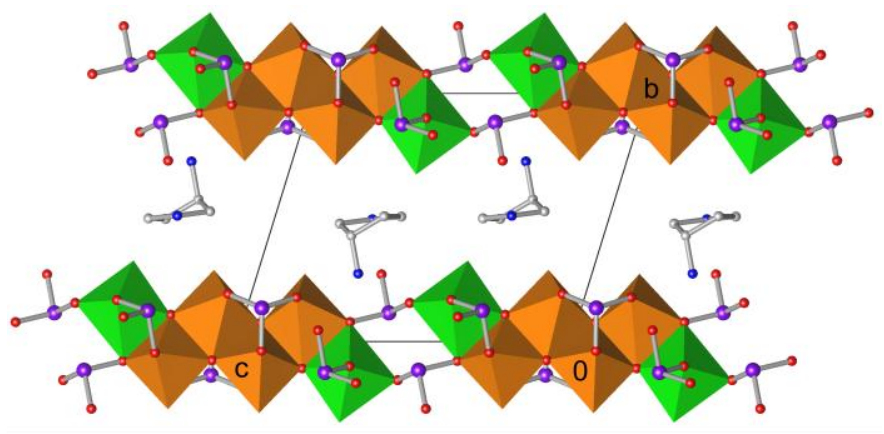

a
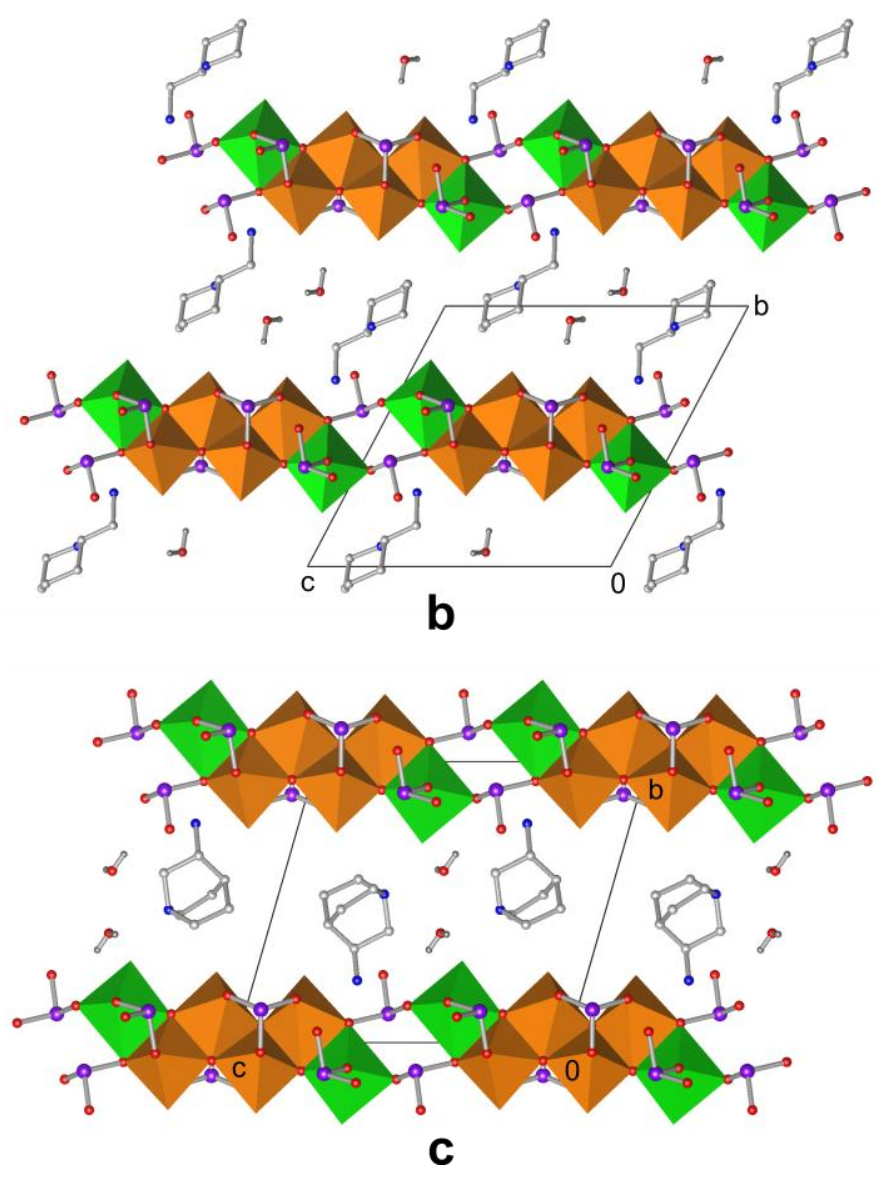

Figure 4. Three-dimensional packing figures of (a) $\left[\mathrm{C}_{4} \mathrm{H}_{12} \mathrm{~N}_{2}\right]\left[\mathrm{V}_{3} \mathrm{O}_{5}\left(\mathrm{SeO}_{3}\right)_{3}\right]$ (4), (b) $\left[\mathrm{C}_{6} \mathrm{H}_{16} \mathrm{~N}_{2}\right]\left[\mathrm{V}_{3} \mathrm{O}_{5}\left(\mathrm{SeO}_{3}\right)_{3}\right] \cdot \mathrm{H}_{2} \mathrm{O}$ (5) and (c) $\left[\mathrm{C}_{7} \mathrm{H}_{14} \mathrm{~N}_{2}\right]\left[\mathrm{V}_{3} \mathrm{O}_{5}\left(\mathrm{SeO}_{3}\right)_{3}\right] \cdot \mathrm{H}_{2} \mathrm{O}(\mathbf{6})$. Green and orange polyhedra represent $\left[\mathrm{V}^{4+} \mathrm{O}_{6}\right]$ and $\left[\mathrm{V}^{5+} \mathrm{O}_{6}\right]$, respectively, while purple, red, blue, white and gray spheres represent selenium, oxygen, nitrogen, carbon and hydrogen, respectively. Organic ammonium cation hydrogen atoms have been omitted for clarity. 
1

2

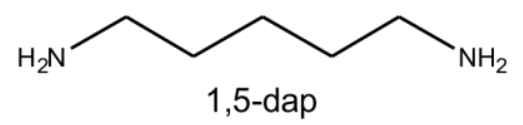<smiles>NCCCCCCCCN</smiles><smiles>CN(C)CCN(C)C</smiles><smiles>NCCCNCCCCNCCCN</smiles>
spermine<smiles>CC1CNC(C)C(C)N1</smiles>

Figure 5. The fourteen amines used in this study. 
Figure 6. Reaction outcomes as a function of conditions and amine identity. 


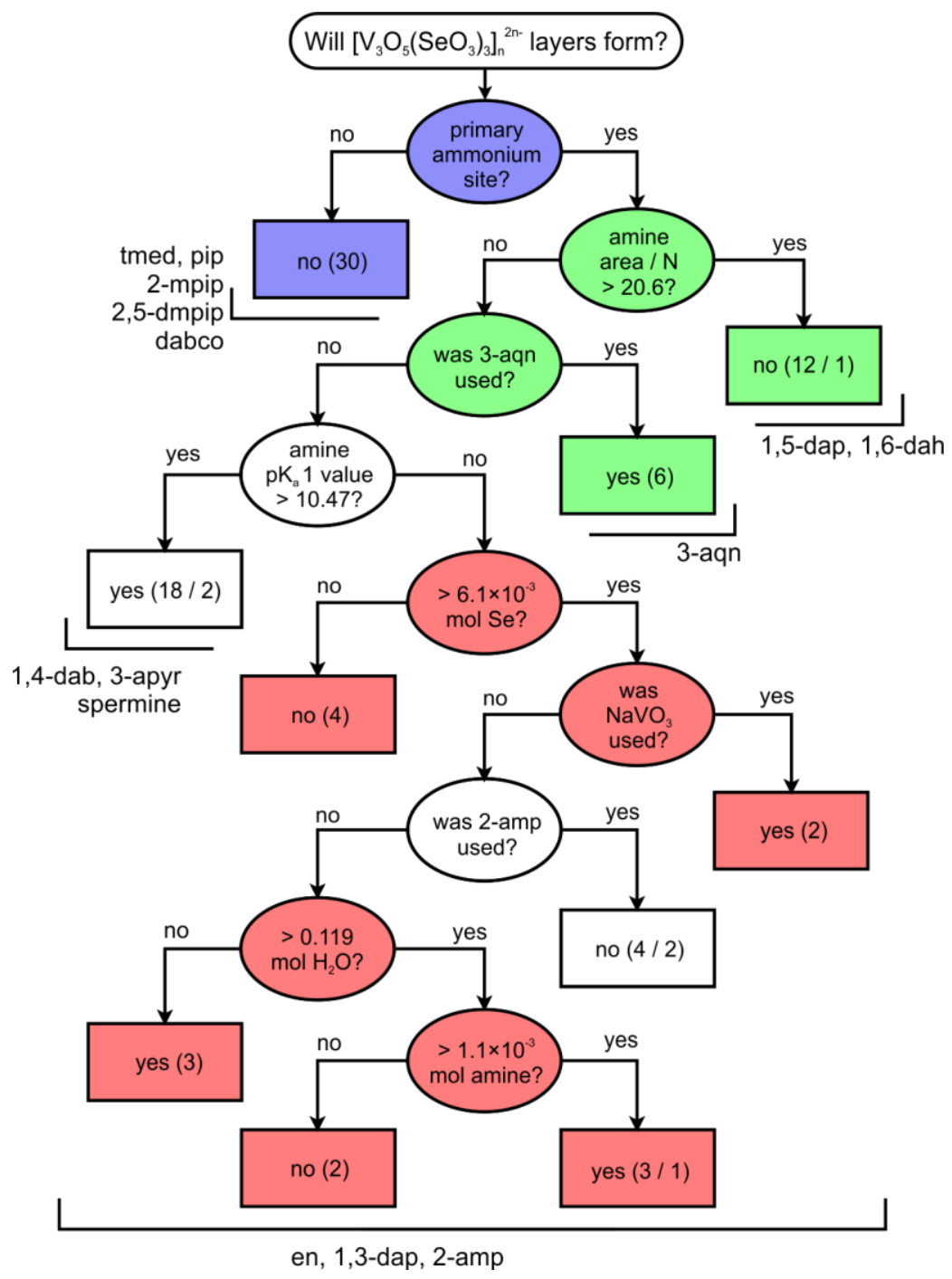

Figure 7. $\left[\mathrm{V}_{3} \mathrm{O}_{5}\left(\mathrm{SeO}_{3}\right)_{3}\right]_{\mathrm{n}}{ }^{2 \mathrm{n}-}$ layer formation decision tree. Selection of primary amines is shown in blue, selection by charge density matching is shown in green, and selection by vanadium source is shown in red. Each reaction bin contains a specific reaction outcome value and numbers of reactions correctly and incorrectly assigned to that bin, respectively. 


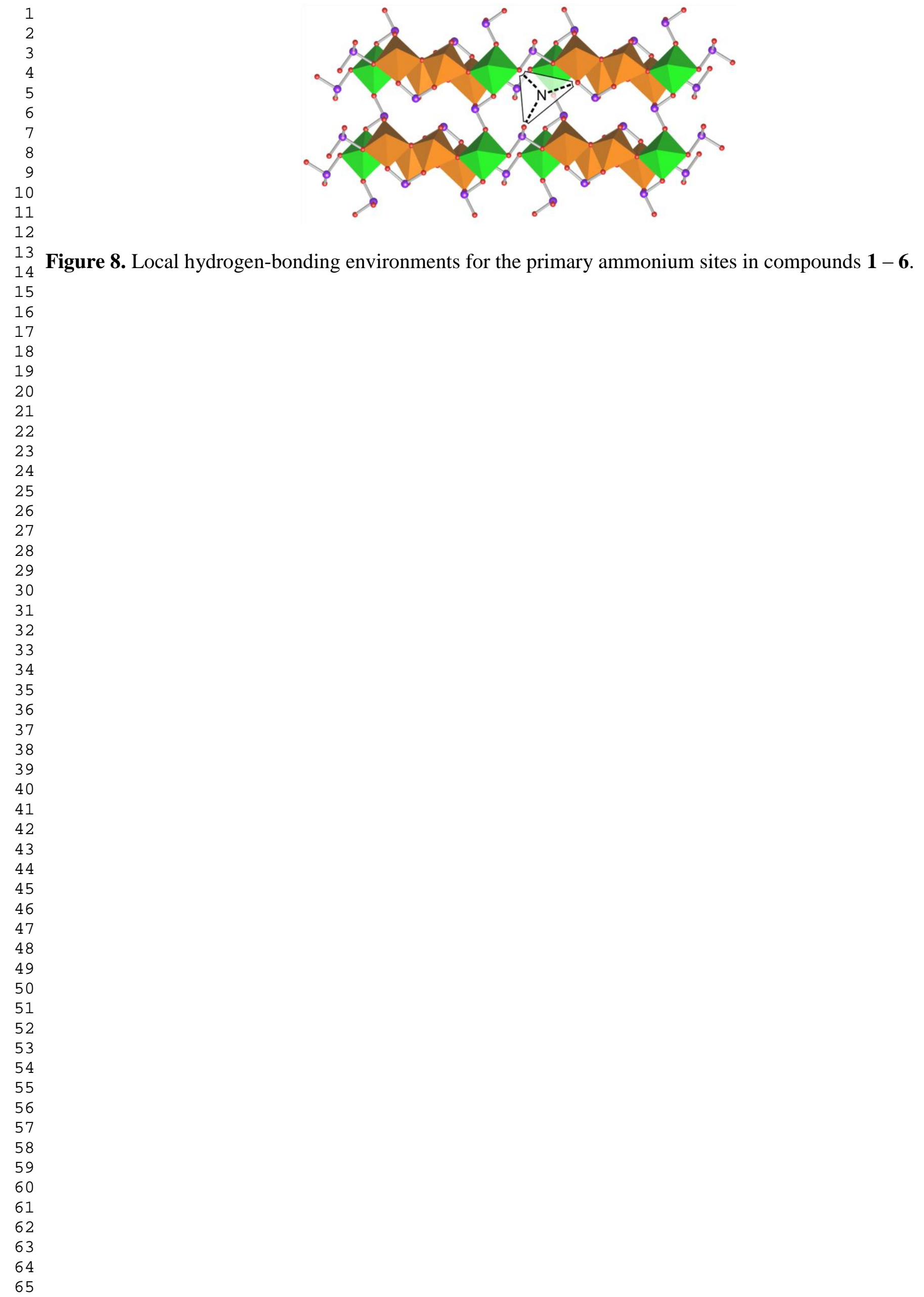




\section{Graphical Abstract}

A cheminformatics approach to understanding structural adaptability of organic inorganic hybrid materials is

presented in which $\left[\mathrm{V}_{3} \mathrm{O}_{5}\left(\mathrm{SeO}_{3}\right)_{3}\right]_{\mathrm{n}}{ }^{2 \mathrm{n}-}$ layers in templated vanadium selenites are the focus. The use of descriptor space exploration, decision tree generation and chemical hypothesis creation enables fundamental understanding of the structural stability under investigation.

15

16

17

18

19

20

21

22

23

24

25

26

27

28

29

30

31

32

33

34

35

36

37

38

39

40

41

42

43

44

45

46

47

48

49

50

51

52

53

54

55

56

57

58

59

60

61

62

63

64

65

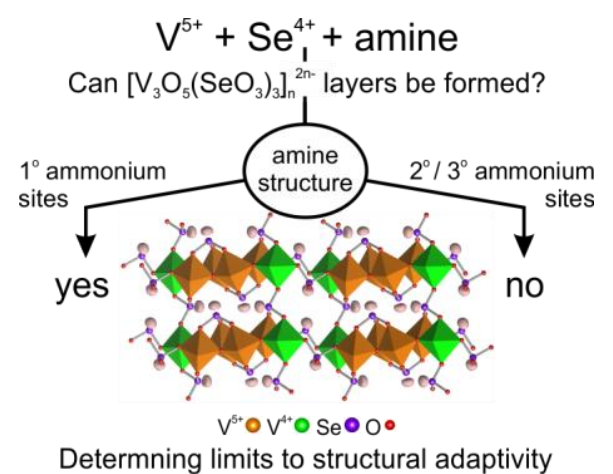


1 [1]. M. T. Anderson, J. T. Vaughey, K. R. Poeppelmeier, Chem. Mater. 5 (1993) 151-65.

[2]. M. T. Anderson, K. B. Greenwood, G. A. Taylor, K. R. Poeppelmeier, Prog. Solid State Chem. 22 (1993) 197-233.

5 [3]. N. W. Grimes, Spectrum (Pretoria, South Africa) 14 (1976) 27-30.

[4]. S. Geller, Z. Kristallogr. 125 (1967) 1-47.

[5]. J. P. Smit, P. C. Stair, K. R. Poeppelmeier, Chem. Eur. J. 12 (2006) 5944-5953.

[6]. V. M. Goldschmidt, Die Naturwissenschaften 21 (1926) 477-485.

[7]. X. Liu, R. Hong, C. Tian, Journal of Materials Science: Materials in Electronics 20 (2009) 323-327.

1 [8]. A. K. Cheetham, C. N. R. Rao, R. K. Feller, Chem. Commun. (2006) 4780-4795.

2 [9]. A. K. Cheetham, G. Ferey, T. Loiseau, Angew. Chem. Int. Ed. 38 (1999) 3268-3292.

[10]. C. S. Cundy, P. A. Cox, Chem. Rev. 103 (2003) 663-701.

[11]. R. C. Haushalter, L. A. Mundi, Chem. Mater. 4 (1992) 31-48.

[12]. C. N. R. Rao, S. Natarajan, S. Neeraj, J. Am. Chem. Soc. 122 (2000) 2810-2817.

[13]. W. O. Haag, Stud. Surf. Sci. Catal. 84 (1994) 1375-94.

[14]. E. C. Glor, S. M. Blau, J. Yeon, M. Zeller, P. Shiv Halasyamani, J. Schrier, A. J. Norquist, J. Solid State Chem. 184 (2011) 1445-1450.

[15]. D. Weber, Zeitschrift fuer Naturforschung, Teil B: Anorganische Chemie, Organische Chemie 33B (1978) 1443-5.

23 [16]. D. Weber, Zeitschrift fuer Naturforschung, Teil B: Anorganische Chemie, Organische Chemie 33B (1978) 862-5.

[17]. A. Kojima, K. Teshima, Y. Shirai, T. Miyasaka, J. Am. Chem. Soc. 131 (2009) 6050-6051.

[18]. J.-H. Im, C.-R. Lee, J.-W. Lee, S.-W. Park, N.-G. Park, Nanoscale 3 (2011) 4088-4093.

[19]. F. Hao, C. C. Stoumpos, D. H. Cao, R. P. H. Chang, M. G. Kanatzidis, Nature Photonics 8 (2014) 489-

494.

[20]. M. M. Lee, J. Teuscher, T. Miyasaka, T. N. Murakami, H. J. Snaith, Science (Washington, DC, United States) 338 (2012) 643-647.

33 [21]. I. C. Smith, E. T. Hoke, D. Solis-Ibarra, M. D. McGehee, H. I. Karunadasa, Angew. Chem., Int. Ed. 53 4 (2014) 11232-11235.

[22]. K. S. Park, Z. Ni, A. P. Cote, J. Y. Choi, R. Huang, F. J. Uribe-Romo, H. K. Chae, M. O'Keeffe, O. M. Yaghi, Proc. Natl. Acad. Sci. 103 (2006) 10186-10191.

[23]. O. M. Yaghi, M. O'Keeffe, N. W. Ockwig, H. K. Chae, M. Eddaoudi, J. Kim, Nature 423 (2003) 705714.

[24]. H. Li, M. Eddaoudi, M. O'Keeffe, M. Yaghi, Nature 402 (1999) 276-279.

[25]. T. Kusukawa, M. Fujita, J. Am. Chem. Soc. 121 (1999) 1397-1398.

[26]. M. Fujita, S.-Y. Su, T. Kusukawa, H. Funaki, K. Ogura, K. Yamaguchi, Angew. Chem., Int. Ed. 37 (1998) 2082-2085.

[27]. F. Baumann, A. Livoreil, W. Kaim, J.-P. Sauvage, Chem. Commun. (1997) 35-36.

[28]. D. B. Amabilino, C. O. Dietrich-Buchecker, A. Livoreil, L. Perez-Garcia, J.-P. Sauvage, J. F. Stoddart, J. Am. Chem. Soc. 118 (1996) 3905-13.

[29]. A. Nourmahnad, M. D. Smith, M. Zeller, G. M. Ferrence, J. Schrier, A. J. Norquist, Inorg. Chem. 54 (2015) 694-703.

[30]. A. Rabenau, Angew. Chem. Int. Ed. 24 (1985) 1026-1040.

[31]. Apex2 v2009.7-0., Bruker AXS Inc.: Madison (WI), USA, 2009.

[32]. A. Altomare, G. Cascarano, C. Giacovazzo, A. Guagliardi, J. Appl. Crystallogr. 26 (1993) 343-50.

[33]. P. W. Betteridge, J. R. Carruthers, R. I. Cooper, K. Prout, D. J. Watkin, J. Appl. Crystallogr. 36 (2003)

1487.

[34]. E. Dowty ATOMS v. 6.0, Shape Software: TN, USA, 2002.

[35]. I. D. Brown, D. Altermatt, Acta Crystallogr. Sect. B 41 (1985) 244-7.

[36]. N. E. Brese, M. O'Keeffe, Acta Crystallogr. Sect. B 47 (1991) 192-7.

[37]. X. Gonze, J. M. Beuken, R. Caracas, F. Detraux, M. Fuchs, G. M. Rignanese, L. Sindic, M. Verstraete, G. Zerah, F. Jollet, M. Torrent, A. Roy, M. Mikami, P. Ghosez, J. Y. Raty, D. C. Allan, Comput. Mater. Sci. 25 (2002) 478-492. 
[38]. X. Gonze, B. Amadon, P. M. Anglade, J. M. Beuken, F. Bottin, P. Boulanger, F. Bruneval, D. Caliste, R. Caracas, M. Cote, T. Deutsch, L. Genovese, P. Ghosez, M. Giantomassi, S. Goedecker, D. R. Hamann, P. Hermet, F. Jollet, G. Jomard, S. Leroux, M. Mancini, S. Mazevet, M. J. T. Oliveira, G. Onida, Y. Pouillon, T. Rangel, G. M. Rignanese, D. Sangalli, R. Shaltaf, M. Torrent, M. J. Verstraete, G. Zerah, J. W. Zwanziger, Comput. Phys. Commun. 180 (2009) 2582-2615.

[39]. K. Momma, F. Izumi, J. Appl. Crystallogr. 41 (2008) 653-658.

[40]. A. Otero-de-la-Roza, M. A. Blanco, A. M. Pendas, V. Luana, Comput. Phys. Commun. 180 (2009) 157166.

[41]. A. Otero-de-la-Roza, E. R. Johnson, V. Luana, Comput. Phys. Commun. 185 (2014) 1007-1018.

[42]. ChemAxon, Marvin 14.10.20.0, ChemAxon (http://www.chemaxon.com), 2014 (last accessed Dec. 17, 2014).

[43]. I. Pasha, A. Choudhury, C. N. R. Rao, Inorg. Chem. 42 (2003) 409-415.

[44]. J. H. Olshansky, K. J. Wiener, M. D. Smith, A. Nourmahnad, M. J. Charles, M. Zeller, J. Schrier, A. J. Norquist, Inorg. Chem. 53 (2014) 12027-12035.

[45]. J. H. Koffer, J. H. Olshansky, M. D. Smith, K. J. Hernandez, M. Zeller, G. M. Ferrence, J. Schrier, A. J. Norquist, Cryst. Growth Des. 13 (2013) 4504-4511.

[46]. J. H. Olshansky, T. Thao Tran, K. J. Hernandez, M. Zeller, P. S. Halasyamani, J. Schrier, A. J. Norquist, Inorg. Chem. 51 (2012) 11040-11048.

[47]. H. Nakano, T. Ozeki, A. Yagasaki, Inorg. Chem. 40 (2001) 1816-1819.

[48]. Z. Lian, C. Huang, H. Zhang, H. Yang, Y. Zhang, X. Yang, J. Chem. Crystallogr. 34 (2004) 489-494.

[49]. Z. Dai, G. Li, Z. Shi, W. Fu, W. Dong, J. Xu, S. Feng, Solid State Sci. 6 (2004) 91-96.

[50]. Z. Dai, Z. Shi, G. Li, X. Chen, X. Lu, Y. Xu, S. Feng, J. Solid State Chem. 172 (2003) 205-211.

[51]. Z. Lian, J. Zhang, Y. Gu, T. Wang, T. Lou, J. Mol. Struct. 919 (2009) 122-127.

[52]. Z. Dai, G. Li, Z. Shi, X. Liu, S. Feng, Inorg. Chem. Commun. 8 (2005) 890-893.

[53]. G. Ferey, J. Fluorine Chem. 72 (1995) 187-93.

[54]. G. Ferey, Chem. Mater. 13 (2001) 3084-3098.

[55]. H. S. Casalongue, S. J. Choyke, A. Narducci Sarjeant, J. Schrier, A. J. Norquist, J. Solid State Chem. 182 (2009) 1297-1303.

[56]. T. R. Veltman, A. K. Stover, A. Narducci Sarjeant, K. M. Ok, P. S. Halasyamani, A. J. Norquist, Inorg. Chem. 45 (2006) 5529-5537.

[57]. D. J. Hubbard, A. R. Johnston, H. Sanchez Casalongue, A. Narducci Sarjeant, A. J. Norquist, Inorg. Chem. 47 (2008) 8518-8525.

[58]. K. R. Heier, A. J. Norquist, C. L. Stern, K. R. Poeppelmeier, Book of Abstracts, 215th ACS National Meeting, Dallas, March 29-April 2 (1998) INOR-211.

[59]. A. J. Norquist, M. B. Doran, D. O'Hare, Inorg. Chem. 44 (2005) 3837-3843.

[60]. G. R. Desiraju, Chem. Commun. (2005) 2995-3001.

[61]. K. B. Chang, M. D. Smith, S. M. Blau, E. C. Glor, M. Zeller, J. Schrier, A. J. Norquist, Cryst. Growth Des. 13 (2013) 2190-2197.

[62]. K. B. Chang, D. J. Hubbard, M. Zeller, J. Schrier, A. J. Norquist, Inorg. Chem. 49 (2010) 5167-5172.

[63]. M. D. Smith, S. M. Blau, K. B. Chang, M. Zeller, J. Schrier, A. J. Norquist, Cryst. Growth Des. 11 (2011) 4213-4219. 